\title{
EFFECT OF INTRA-RADICULAR REHABILITATION TECHNIQUES ON PUSH-OUT BOND STRENGTH OF FIBER-REINFORCED POSTS IN EXTREMELY FLARED CANALS
}

\author{
Roqaia Mohammad Al Assar*
}

\begin{abstract}
Statement of the problem: Which technique should be followed to restore excessively flared canals, augmentation of intra-radicular dentin or customization of fiber post? The question asked by many practitioners.

Purpose: To compare the effect of different intra-radicular rehabilitation techniques on pushout bond strength of fiber posts in extremely flared canals.

Materials and Methods: Eighteen freshly extracted human maxillary central incisors roots were endodontically treated and embedded in acrylic blocks. The root canals were excessively flared and divided into six groups according to the technique of intra-radicular rehabilitation; Gr1: Augmentation of intra-radicular dentin by bulk-fill packable composite then cementation of Glassix plus post, Gr2: Augmentation of intra-radicular dentin by bulk-fill packable composite and direct use of Glassix plus post, Gr3: Augmentation of intra-radicular dentin by flowable composite then cementation of Glassix plus post, Gr4: Augmentation of intra-radicular dentin by flowable composite and direct use of Glassix plus post, Gr5: Customization of Glassix plus post by bulk-fill packable composite then cementation of the customized post, and Gr6: Customization of Glassix plus post by bulk-fill packable composite with simultaneous cementation. The roots were sectioned, thermocycled and the specimens were subjected to push-out test in universal testing machine. The maximum failure load was recorded and used to calculate the push-out bond strength. Data was statistically analyzed and failure mode was assessed using magnifying lens.
\end{abstract}

Results: The highest mean value was recorded in Gr1, followed by Gr2, then Gr4, Gr3, Gr5, with the lowest mean recorded in Gr6. ANOVA test revealed the difference was statistically significant $(\mathrm{p}=0.0028)$. Tukey post hoc test revealed no significant difference between groups $1,2,3,4$. Gr3 and Gr4 were not significantly different from all other groups.

Conclusions: 1) Higher bond strengths are achievable with augmentation of excessively flared canals compared to customization of prefabricated fiber posts, 2) Augmentation of intra-radicular dentin is highly recommended by bulk-fill packable composite rather than flowable composite,

*Lecturer of Crowns and Bridges, Faculty of Dental Medicine for Girls, Al Azhar University. 
3) Cementation of light-transmitting post is an important step after augmentation of root dentin by bulk-fill composite, and 4) Use of light-transmitting post in conjunction with bulk-fill composite exhibits synergetic effect in curing depth manifested by high bond strengths. However, the use of one step-single curing method is not recommended.

Clinical Significance: For extremely flared canals, it is advisable to use bulk-fill packable composite for augmentation of root dentin, followed by adhesive cementation of light-transmitting post. Always remember that augmentation of intra-radicular dentin is much better than customization of fiber post.

\section{INTRODUCTION}

Restoring extremely flared canals by post and core system is considered a unique challenge to the clinician. The root canals become flared as a result of extensive caries, trauma to immature tooth, pulpal pathosis, iatrogenic or endodontic misadventure or idiopathic causes. ${ }^{1}$ In this situation, cast post is contraindicated as it may cause unfavorable root fracture, shadowing and graying of root and discoloration at the gingival margins. ${ }^{2,3}$

Instead, fiber post has many advantages. It is more flexible than metal post and has approximately the same modulus of elasticity as dentin. ${ }^{4}$ When bonded in place with resin cement, forces would be distributed more evenly in the root, resulting in fewer root fractures. ${ }^{4}$ Also fiber post reinforces the root canal and aids in retention of the core material. ${ }^{5}$ However, the mismatch between the diameter of the prefabricated fiber post and that of excessively flared canal presented a clinical problem. ${ }^{6,7}$

Therefore, the intra-radicular rehabilitations either by augmentation of intra-radicular dentin or customization of fiber post were suggested to adapt the root canal to the fiber post or to adapt the fiber post to the canal, respectively., ${ }^{5,-10}$ The main goal of intra-radicular rehabilitation is to reinforce the remaining dentin thickness less than $2 \mathrm{~mm}$ before post placement. In addition, to increase adaptation between a prefabricated post and flared canal that leads to better retention. ${ }^{10}$

The techniques suggested for intra-radicular rehabilitation based on achieving the monoblock effect through the following three principles: first; the selected post and core system used to restore flared canals should have Elastic Modulus similar to dentin, second; adhesive bonding of composite resin andlor resin cement to radicular dentin, third; composite resin can be used for intra-radicular rehabilitation as it absorbs and distributes forces in a more uniform manner and increases resistance to fracture, thus providing improved prognosis. ${ }^{11}$ Moreover, the introduction of commercially available light-transmitting posts allows light polymerization by transillumination that effectively polymerizes the composite along the entire length of the intra-radicular preparation.

In 2014, comprehensive techniques for intraradicular rehabilitation of weakened anterior teeth were compared. It was concluded that cast post should not be used to strengthen structurally compromised and weakened roots. ${ }^{5}$ Consequently, a combination of flowable composite resin and fiber post could help in reinforcing flared root canals. ${ }^{5}$ In addition, it was reported that multidisciplinary management of a structurally weakened root by reinforcement with flowable composite and glass fiber post is a simple and efficient procedure with excellent esthetic and functional results. ${ }^{8}$

In 2018, bond strength values of glass fiber post to flared root canals reinforced with different materials were studied. Root augmentation with conventional and bulk-fill composite resins showed the highest bond strength values; however, the bulkfill composite was the only material able to maintain high bond strength values in all root canal regions. It was concluded that augmentation of root dentin with bulk-fill composite is an effective option for 
flared canals before cementation of a prefabricated fiber post. ${ }^{9}$

The push-out test is an appropriate method to measure the bond strength inside root canals. As a result of the applied load, shear stresses are introduced at the interface with maximum value occurring at the region near the top face, resulting in a better simulation of the stresses occurring in clinical conditions. ${ }^{12}$

Therefore, the aim of this in vitro study was to investigate the effect of intra-radicular rehabilitation technique on push-out bond strength of fiber reinforced post in excessively flared root canal. The null hypothesis tested was that intraradicular rehabilitation technique has no influence on push-out bond strength of fiber reinforced post in excessively flared root canal.

\section{MATERIALS AND METHODS}

To conduct this study, eighteen freshly extracted human maxillary central incisors were selected in accordance with guidelines from research ethics committee approval of Faculty of Dental Medicine for Girls, Al Azhar University. The teeth were rinsed under running water, cleaned and stored in $0.1 \%$ thymol sol at room temperature until use.

\section{Endodontic procedure}

The teeth were decoronated, coronal to the labial CEJ using a diamond double-faced disk (910D; Diatech; Switzerland) mounted in a low speed hand-piece with water coolant. The working length was determined directly by subtracting $1.0 \mathrm{~mm}$ from the real root length detected by introducing a number $10 \mathrm{~K}$-file (Maillefer, Dentsply) until it was visible through the apical foramen. Only similar root lengths $(16 \pm 0.5 \mathrm{~mm})$ were accepted. A stepback mechanical instrumentation technique was done by the same operator using K-files until the same size (\#50 file; Maillefer, Dentsply). Canals were irrigated with $1 \mathrm{ml}$ of $0.5 \% \mathrm{NaOCl}$, dried with sterile absorbent paper points (Maillefer, Dentsply) then obturated with gutta-percha points (Maillefer, Dentsply) and eugenol-free sealer (Roeko, Coltene, Germany) using lateral condensation technique. An acrylic resin (Acrostone, Egypt) block was constructed by embedding each root in a special cylindrical shaped stainless steel block former (20 $\mathrm{mm}$ length and $15 \mathrm{~mm}$ diameter) by the aid of a vertical holding device.

\section{Post-space preparation}

Using Gates Glidden drills (\#2\&3) (Maillefer, Dentsply) in a low speed hand-piece; gutta-percha was removed till the length of $11 \mathrm{~mm}$ leaving $5 \mathrm{~mm}$ for apical seal. The canals were cleaned with water and dried with paper points. Glassix plus post drill (\#2, Harald Nordin, Switzerland) of $1.2 \mathrm{~mm}$ in diameter was inserted for $11 \mathrm{~mm}$ depth. A tapered diamond stone (D15923 Kennesaw, USA) of $8 \mathrm{~mm}$ length and $2.2 \mathrm{~mm}$ diameter was used to obtain a standardized flaring. Only the coronal $8 \mathrm{~mm}$ was flared leaving the apical $3 \mathrm{~mm}$ of post space without flaring to ensure a centralized placement of the post in the flared canal. ${ }^{13}$

\section{Samples grouping}

The samples were divided randomly into six groups, according to the intra-radicular rehabilitation technique; (Figure 1)

Gr 1: Augmentation of intra-radicular dentin by bulk-fill packable composite, followed by cementation of Glassix plus post;

Intra-radicular dentin walls were etched by $36 \%$ phosphoric acid gel (Blue Etch, StalowaWola, Polska) for 15 seconds, followed by rinsing with water and drying with paper points. Double layers of Single Bond (3M, ESPE, Germany) were applied on the entire canal surface as recommended by the manufacturer with the aid of a microbrush. The $1^{\text {st }}$ layer was kept to react for 10 seconds then the $2^{\text {nd }}$ was applied and light-cured by positioning the tip of the light-curing unit (3M, ESPE, Germany) at the canal entrance for 20 seconds. Bulk-fill packable 
composite (x-tra fil, Voco, Germany) was used to fill the flared canal. After that, a prefabricated Glassix plus (\#2 light-transmitting fiber post, Nordin, Switzerland) was lubricated with glycerin gel (PURE Misr, Egypt) using microbrush then inserted in the canal and centralized in position. Excess composite was removed by excavator and then the tip of the light-curing unit was placed over the post and activated for 20 seconds. The fiber post was subsequently removed from the canal. Additional 20 seconds light curing was recommended. Finally, the post space was thoroughly washed by water using endo irrigation needle (2-Side Vent, transcodent ${ }^{\mathrm{TM}}$, Sulzer, Deutschland $\mathrm{GmbH}$ ) to remove the effect of lubricant and then dried. The post was cleaned by alcohol saturated gauze and cemented using G-CEM (dual cure, self-adhesive, GC Europe), according to manufacturer's recommendations.

Gr2: Augmentation of intra-radicular dentin by bulk-fill packable composite and direct use of Glassix plus post (without cementation);

Intra-radicular dentin walls were etched, rinsed, dried and bonded as Gr1. Then x-tra fil packable composite resin was used to fill the flared canal and a prefabricated Glassix plus post (\#2) was inserted and centralized in position. Excess composite was removed and then the tip of the light-curing unit was placed over the post and activated for 40 seconds.

Gr3: Augmentation of intra-radicular dentin by flowable composite then cementation of Glassix plus post;

Intra-radicular dentin walls were etched, rinsed, dried and bonded as Gr1. Then a prefabricated Glassix plus post (\#2) was lubricated with glycerin gel using microbrush then inserted in the canal and centralized in position. After that, the flowable composite (Any-Com Flow, nano-hybrid flowable composite reinforced by zirconium fillers, Mediclus Co. Ltd, Korea) was applied with a long, thin and metallic point provided by the manufacturer to fill the flared canal from the apex to the cervical portion to avoid air pockets. The tip of the light-curing unit was placed over the post and activated for 20 seconds. The fiber post was subsequently removed from the canal. Additional 20 seconds light curing was recommended. Finally, the post space was thoroughly washed and dried. The post was cleaned by alcohol saturated gauze and cemented using G-CEM as Gr1 samples.

Gr4: Augmentation of intra-radicular dentin by flowable composite and direct use of Glassix plus post (without cementation);

Intra-radicular dentin walls were etched, rinsed, dried and bonded as Gr1. Any-Com Flow was injected from the apex to the cervical portion to avoid air pockets. Then a prefabricated Glassix plus post (\#2) was inserted and centralized in position. Excess resin was removed and the tip of the lightcuring unit was placed over the post and activated for 40 seconds.

Gr5: Customization of Glassix plus post by bulkfill packable composite then cementation of the customized post (Two step-double curing method);

The canal was lubricated with glycerin gel using microbrush. A prefabricated Glassix plus post (\#2) was coated by a layer of bulk-fill packable composite (x-tra fil, Voco) then inserted into the canal and partially light cured for 20 seconds. After that the customized post was removed, and light cured for

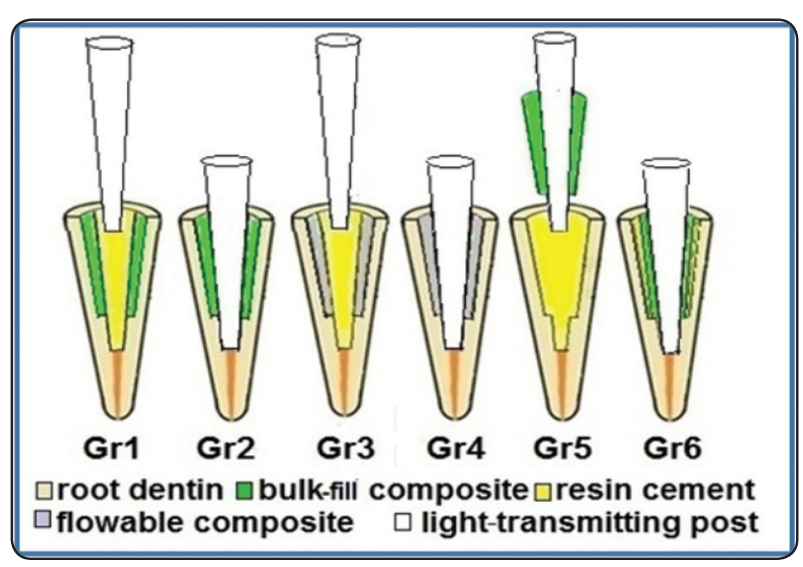

Fig. (1): Samples grouping. 
additional 20 seconds. The canal was rinsed to remove the effect of any lubricant and dried. The customized post was cemented using G-CEM and light cured.

Gr6: Customization of Glassix plus post by bulk-fill packable composite with simultaneous cementation (One step- single curing method);

A prefabricated Glassix plus post (\#2) was coated by a layer of $x$-tra fil composite and inserted to record the canal shape, then removed gently. In one step, G-CEM resin cement was applied in the canal, followed by insertion of the unpolymerized customized post, the excess was removed and the assembly was light cured for 40 seconds.

\section{Thermocycling}

All samples of each group were subjected to 3000 thermocycle shocks between water baths at 5 - $55^{\circ} \mathrm{C}$, with a dwell time of 30 seconds using thermocycling device (Ropota, automated, BIL GE, Turkey).

\section{Push out bond strength test}

Each sample was transversely sectioned perpendicular to the long axis of the root using a water-cooled precision saw (Isomet1000, Buehler Ltd.) to obtain three sections of $2 \mathrm{~mm}$ thicknesses. Each section was coded and photographed from apical and coronal surfaces using a stereomicroscope (SZ-PT; Olympus, Tokyo, Japan) at an original magnification of $65 \mathrm{x}$. Calibration was performed by comparing an object of known length, a ruler in this study, using the "Set Scale" tool generated by the image analysis software (Image J; NIH, Bethesda, MD). The diameter of the post was then measured and the radius was calculated. Each specimen was secured in a custom made loading fixture and subjected to compressive loading via a computer controlled materials testing machine (Model 3345; Instron Industrial Products, Norwood, MA, USA). The plunger tip was sized and positioned to touch only the post, without stressing the surrounding filling, in apical coronal direction to push the post toward the larger diameter. The maximum failure load was recorded in $\mathrm{N}$ and converted into $\mathrm{MPa}$ using computer software (Bluehill Lite Software, Instron $\left.{ }^{\circledR}\right)$. The bond strength was calculated according to the following formula:

$\mathrm{BS}=\mathrm{F} / \mathrm{A}$, and $\mathrm{A}=\left(3.14 \mathrm{x}_{1} \mathrm{X} 3.14 \mathrm{x}_{2}\right) \mathrm{L}$, where $\mathrm{F}$ is the applied load, A is the area of the post/ dentin surface, $r_{1}$ apical radius, $r_{2}$ coronal one, $\mathrm{L}=\left[\left(\mathrm{r}_{1}-\mathrm{r}_{2}\right) 2+\mathrm{h}^{2}\right]^{0.5}$, and $\mathrm{h}$ is the thickness of the specimen in millimeters. ${ }^{14}$

\section{Statistical analysis}

ANOVA was used in testing significance for the effect of intra-radicular rehabilitation technique on push-out bond strength. Tukey's post-hoc test was used when ANOVA test was significant.

\section{Failure mode assessment}

Mode of failure was assessed under magnifying lens (10X, Optics Co, Ltd, China) and scored as follows; Score 1: Adhesive failure at composite or cement/root dentin interface. Score 2: Adhesive failure at composite/cement interface. Score 3: Adhesive failure at composite or cement/ post interface. Score 4: Cohesive failure within composite resin or cement layer. (Figure 2)

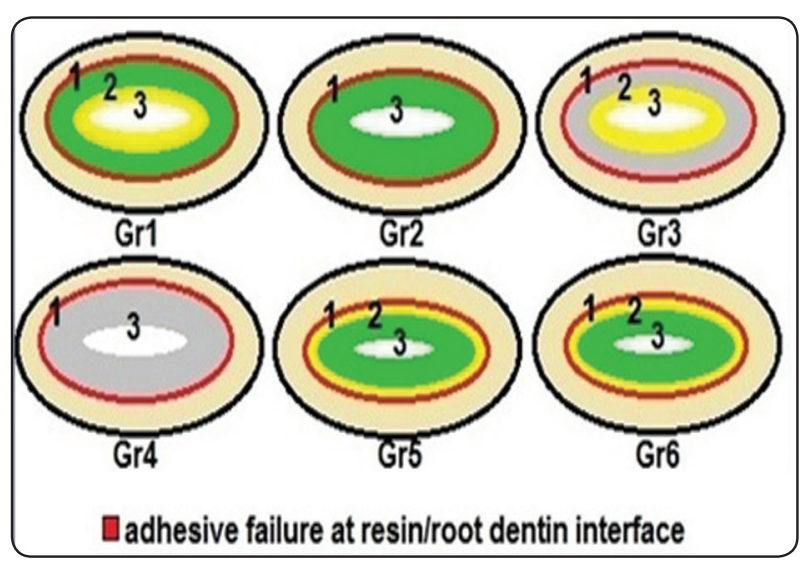

Fig. (2): "Score 1" mode of failure in all groups. 


\section{RESULTS}

\section{Statistical analysis of push-out strength;}

The highest mean value was recorded in Gr1, followed by Gr2, then Gr4, Gr3, Gr5, with the lowest mean recorded in Gr6. ANOVA test revealed that the difference between groups was statistically significant $(\mathrm{p}=0.0028)$. Tukey's post hoc test revealed no significant difference between groups 1,2,3,4. Group 2 was significantly different from group 6. Groups $3 \& 4$ were not significantly different from all other groups. (Tables 1, Figure 3)

\section{Mode of failure analysis}

On examination of the fractured samples, it was observed that Score 1 (i.e. adhesive failure at composite or cement/root dentin interface) was the most common failure mode in all groups. (Figure 2)

TABLE (1A): Mean \pm standard deviation of pushout bond strength of fiber post and significance of the difference between different intra-radicular rehabilitation techniques (ANOVA test).

\begin{tabular}{|c|c|c|c|}
\hline Groups & $\begin{array}{c}\text { Push-out bond strength } \\
\text { (in MPa) }\end{array}$ & F & P \\
\cline { 1 - 2 } Gr_1 & $0.990^{a} \pm 0.22$ & \multirow{2}{*}{4.36} & $0.0028^{*}$ \\
\hline Gr_2 & $0.968^{\mathrm{a}, \mathrm{b}} \pm 0.21$ & & \\
\hline Gr_3 & $0.757^{\mathrm{a}, \mathrm{b}, \mathrm{c} \pm 0.12}$ & & \\
\cline { 1 - 2 } $\mathrm{Gr}_{-} 4$ & $0.778^{\mathrm{a}, \mathrm{b}, \mathrm{c} \pm 0.16}$ & & \\
\cline { 1 - 2 } Gr_5 & $0.720^{\mathrm{b}, \mathrm{c} \pm 0.17}$ & & \\
\hline Gr_6 & $0.695^{\mathrm{c}} \pm 0.14$ & & \\
\hline
\end{tabular}

Significance level $p \leq 0.05, *$ significant, $n s=n o n$-significant

Tukey's post hoc test: means sharing the same superscript letter are not significantly different
TABLE (1B): Detailed results of Tukey's post hoc test for significance of the difference between different intra-radicular rehabilitation techniques.

\begin{tabular}{|l|c|c|c|c|c|}
\hline & Group 2 & Group 3 & Group 4 & Group 5 & Group 6 \\
\hline Gr 1 & $\mathrm{p}=0.9998 \mathrm{~ns}$ & $\mathrm{p}=0.1002 \mathrm{~ns}$ & $\mathrm{p}=0.1657 \mathrm{~ns}$ & $\mathrm{p}=0.0369^{*}$ & $\mathrm{p}=0.0176^{*}$ \\
\hline Gr 2 & & $\mathrm{p}=0.1695 \mathrm{~ns}$ & $\mathrm{p}=0.2649 \mathrm{~ns}$ & $\mathrm{p}=0.0679 \mathrm{~ns}$ & $\mathrm{p}=0.0339^{*}$ \\
\hline Gr 3 & & & $\mathrm{p}=0.9999 \mathrm{~ns}$ & $\mathrm{p}=0.9981 \mathrm{~ns}$ & $\mathrm{p}=0.9792 \mathrm{~ns}$ \\
\hline Gr 4 & & & & $\mathrm{p}=0.9845 \mathrm{~ns}$ & $\mathrm{p}=0.9291 \mathrm{~ns}$ \\
\hline Gr 5 & & & & & $\mathrm{p}=0.9997 \mathrm{~ns}$ \\
\hline
\end{tabular}

Significance level $p \leq 0.05, *$ significant, $n s=$ non-significant

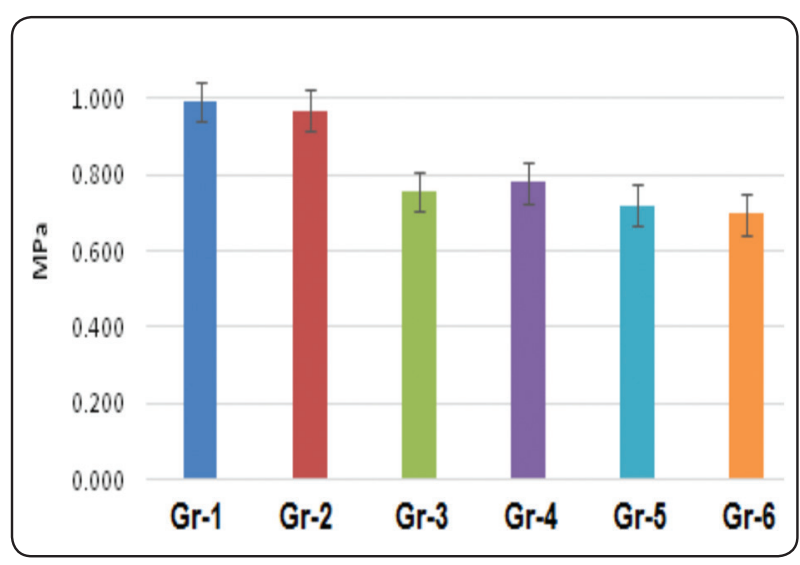

Fig. (3): Bar chart showing mean values of Push-out bond strength $(\mathrm{MPa})$ in different groups

\section{DISCUSSION}

Augmentation (or reinforcement) of intraradicular dentin and customization (or relining) of fiber post are two clinical options recommended to increase adaptation of prefabricated fiber reinforced posts to extremely flared canals. ${ }^{8-10}$ The difference between both strategies is based on the number and type of interfacial surfaces that form the monoblock system. This study suggested different techniques used to strengthen structurally compromised and weakened roots, using the introduced innovative composite resin materials. 
There is a growing trend among practitioners to use bulk-fill composite because of its more simplified procedures. ${ }^{15}$ Many advantages have been reported for bulk-fill materials over conventional composite..$^{15}$ First, regarding the chemical curing properties such as depth of cure and degree of conversion, the bulk fill composite (either packable or flowable) were superior. It was reported the possibility of adequately light-curing these materials up to 4-6 mm at once. ${ }^{15-}$ ${ }^{19}$ Second, in regards to the mechanical properties such as top hardness, bottom hardness, flexural strength, compressive strength and tensile strength, the packable bulk-fill composite tends to be comparable to the conventional composite..$^{20}$ Third, the polymerization stress was lower in flowable and packable bulk-fill composite, while the results were inconsistent in regards to the polymerization shrinkage. ${ }^{20}$ Fourth, concerning the bond strength and microleakage, they tend to be superior in the flowable bulk-fill composite. ${ }^{20}$

Add to ease and quick manipulation, the choice of flowable composite for root augmentation was based on researches that recommended it for restorative purposes, particularly with endodontic therapy. ${ }^{21-23}$ It was reported that flowable composite resins reveal great capabilities to reinforce and strengthen the weakened roots by changing the internal shape of the canal, increasing their thickness and rendering them more resistant to fracture. ${ }^{24}$

The results of the present study revealed a significant effect of intra-radicular rehabilitation technique on push-out bond strength. Therefore, the null-hypothesis was rejected. The results were explained depending on the quality of adhesive bond at interfaces and failure pattern, as well. ${ }^{25}$

In this study, groups $(1 \& 2)$ recorded the highest push-out bond strength among all groups. The main explanation was directed towards the minimal polymerization shrinkage of bulk-fill composite coupled by polymerization stress relieving properties. ${ }^{26-28}$ Therefore, augmentation of intraradicular dentin by bulk-fill composite results in minimal shrinkage and solves the potential problem of using conventional composite resin within the root canal, which is shrinkage towards the post and away from the dentinal walls thus leaving a gap at composite/dentin interface. ${ }^{29}$ These results coincided with Bakaus et $\mathrm{al}^{9}$ study in which root augmentation with bulk-fill composite resin showed the highest bond strength values in all regions. Therefore, it is an effective option for flared root canals before cementation of a prefabricated fiber post. ${ }^{9}$ In addition, as expected, Gr1 recorded higher bond strength values than $\mathrm{Gr} 2$ because of the presence of resin cement layer which enhanced the chemical bond between the light-transmitting fiber post and the bulk-fill composite resin. ${ }^{10}$

In groups (3\&4), the bond strength values at flowable composite/root dentin interface were lower than that in groups $(1 \& 2)$ where bulk-fill packable composite was used. Although, Any-Com Flow showed better mechanical properties due to the presence of zirconia nano-particle fillers, increasing the filler content potentially reduces reactive resin matrix, compromising adhesive bonding of resin composites to root dentin. ${ }^{30}$ These results agreed with Alkhudhairy and Vohra ${ }^{31}$ who concluded that zirconia nano-hybrid filler resin material has comparatively high compressive strength and low bond strength making them suitable for clinical applications in posterior region with favorable bonding conditions. However, despite the use of resin cement in Gr3, they recorded lower push-out bond strength values than Gr4. This may be attributed to the different coefficient of thermal expansion and contraction during thermocycling that deteriorated the bond at the resin cement/flowable composite and the resin cement/fiber post interfaces. ${ }^{32}$

On the other hand, customization of fiber post in groups (5\&6) scored the lowest push-out bond strengths among all groups. Although the fiber post wasrelined by thebulk-fillcomposite, the deteriorated bond at the cement/root dentin interface as a result of the thermal coefficient mismatch greatly decreased the push-out bond strength values. ${ }^{32}$ The cement/ 
root dentin interface is considered as the weakest link in post cementation, and the use of cement with proper mechanical properties is essential for adequate post retention..$^{10}$ Besides, depending only on the ability of light transmission via translucent post by using 'single curing method' seemed to be insufficient for conversion degree of resin cement at the interface. ${ }^{33}$ However, the difference between Gr5 and Gr6 was insignificant because the bulkfill composite is more translucent, which allows more light to pass through the body of the material to enhance polymerization in deep locations. ${ }^{34} \mathrm{In}$ addition, according to the manufacturer, the bulkfill composite contains the "initiator booster" (ivocerin) of a higher photocuring activity than the camphorquinone/amine system because of its higher absorption in the wavelength region between 400 and $450 \mathrm{~nm}$ and ability to form at least two free radicals to initiate the radical polymerization. ${ }^{35}$

Adhesive failure at the resin/root dentin interface was the most common failure pattern observed in all groups. This may be related directly to the difficult bonding process to radicular dentin due to the presence of smear layer, ${ }^{36}$ the degradation of dentin collagen, ${ }^{37}$ the effect of irrigant solution, the regional differences in the density of the dentinal tubules,$^{38}$ and the fluidity of the bonding materials ${ }^{39}$ are all variables that can possibly influence the quality of adhesion at the resin/dentin interface. Another possible explanation may be related to that in light-cured composites, a rapid conversion induces a correspondingly rapid increase in composite stiffness, causing high shrinkage stresses at the resin/root dentin interface. Such stresses may disrupt the bonding between the composite and the cavity walls. ${ }^{40} \mathrm{~A}$ third explanation was due to the external configuration of the Glassix plus post that improved retention at resin/post interface, shifting the failure to the resin/root dentin interface.

Regarding all groups, although the failure occurred at the resin/root dentin interface, bonding of bulk-fill composite to root dentin was stronger than bonding of flowable composite and resin cement.
This may be attributed to the hybrid layer with resin tags formed by the different resin materials. ${ }^{41} \mathrm{Al}$ though the better penetration of resin cement and flowable composite in the dentinal tubules, the distribution of stresses occurring on the fibers distributed throughout the bulk-fill composite's matrix enhance the push-out bond strength at the interface..$^{42}$

The use of self-adhesive resin cement in groups (5\&6) was one of limitations of this study as complete removal of the smear layer by using totaletch bonding system may affect the results.

\section{CONCLUSIONS}

Within the limitations of the study, the following could be concluded; 1) Higher bond strengths are achievable with augmentation of excessively flared canals compared to customization of prefabricated fiber posts, 2) Augmentation of intra-radicular dentin is highly recommended by bulk-fill composite rather than flowable composite, 3) Cementation of light-transmitting fiber post is an important step after augmentation of root dentin by bulk-fill composite, and 4) Use of light-transmitting fiber post in conjunction with bulk-fill composite exhibits synergetic effect in curing depth manifested by high bond strengths. However, the use of one step-single curing method is not recommended.

\section{ACKNOWLEDGMENTS}

The author thanks Prof. Dr. Mona H. Mandour, Professor of Crowns and Bridges, Faculty of Dental Medicine for Girls, Al Azhar University, for comments that greatly improved the manuscript.

\section{REFERENCES}

1. Conclaves LA, Vansan LPV, Paulino SV, Neto MS. Fracture resistance of weakened roots restored with a transilluminating post and adhesive restorative materials. J Prosthet Dent 2006; 96:339-44.

2. Davy DT, Dilley GL. Determination of stress patterns in root filled teeth incorporating various dowel design. J Dent Res 1981; 60:1301-10. 
3. Deutsch AS, Cavallari J, Musikant BL, Silverstein L, Lepley J, Petroni G. Root fracture and design of prefabricated post. J Prosthet Dent 1985; 53(5):637-40.

4. Tait CM, Ricketts DN, Higgins AJ. Weakened anterior roots intra-radicular rehabilitation. Br Dent J 2005; 198(10):609-17.

5. Rayyan MM. Comprehensive techniques for intra-radicular rehabilitation of weakened anterior teeth. Egyptian Dent J 2014; 60:1289-97.

6. D'Arcangelo C, Cinelli M, Angelis F, D'Amario M. The effect of resin cement film thickness on the pull-out strength of a fiber-reinforced post system. J Prosthet Dent 2007; 98:193-8.

7. Leixeira CS, Silva YT, Sousa-Neto MD. Bond strength of fiber posts to weakened roots after resin restoration with different light-curing times. J Endod 2009; 35:1034-9.

8. Chandu GS, Hema BS, Hombesh MN, Huddar D. Intraradicular rehabilitation of tooth using composite resin with light transmitting post - A Case Report. Sch J Dent Sci 2015; 2(1):6-9.

9. Bakaus TE, Gruber YL, Reis A, Gomes OMM, Gomes GM. Bond strength values of fiber glass post to flared root canals reinforced with different materials. Braz. Oral Res J 2018; 32-13.

10. Al Assar RM, Abd El-Ghani OS, Mandour MH. Effect of relining, cement type, and thermocycling on push-out bond strength of fiber reinforced posts. Future Dent J 2015; 1:13-22.

11. Lui JL. Composite resin reinforcement of flared canals using light-transmitting plastic posts. Quintessence Int 1994; 25: $313-8$.

12. Goracci C, Tavares AU, Fabianelli A, Monticelli F, Raffaelli O, Cardoso PC. The adhesion between fiber posts and root canal walls: Comparison between microtensile and push-out bond strength measurements. Eur J Oral Sci 2004; 112: 353-61.

13. Egilmez F, Ergun G, Cekic-Nagas I, Vallittu PK, Lassila LV. Influence of cement thickness on the bond strength of tooth-colored posts to root dentin after thermal cycling. Acta Odont Scand 2012; 71(1):175-82.

14. Nagas E, Cehreli ZC, Durmaz V, Vallittu PK, Lassila LV. Regional push-out bond strength and coronal microleakage of Resilon after different light-curing methods. J En$\operatorname{dod} 2007$; 33(12):1464-8.
15. Leprince JG, Palin WM, Vanacker J, Sabbagh J, Devaux J, Leloup G. Physico-mechanical characteristics of commercially available bulk-fill composites. J Dent 2014; 42(8): 993-1000.

16. Benetti AR, Havndrup-Pedersen C, Honoré D, Pedersen MK, Pallesen U. Bulk-fill resin composites: polymerization contraction, depth of cure, and gap formation. Oper Dent 2015; 40(2):190-200.

17. Ilie N, Stark K. Effect of different curing protocols on the mechanical properties of low-viscosity bulk-fill composites. Clin Oral Investig 2015; 19(2):271-9.

18. Ende A, Munck J, Landuyt KL, Poitevin A, Peumans M, Meerbeek B. Bulk-filling of high C-factor posterior cavities: effect on adhesion to cavity-bottom dentin. Dent Mater 2013; 29(3):269-77.

19. Ilie N, Stark K. Curing behavior of high-viscosity bulk-fill composites. J Dent 2014; 42(8):977-85.

20. Edrees NSA, Amer HSA, Abdelaziz KHM, Alajam W. Benefits and drawbacks of bulk-fill dental composites: A systematic review. EJPMR 2017; 4(10): 124-37.

21. Goncalves LA, Vansan LP, Paulino SM, Neto MD. Fracture resistance of weakened roots restored with a transilluminating post and adhesive restorative materials. J Prosthet Dent 2006; 96:339-44.

22. Lui JL. Enhanced post crown retention in resin composite reinforced, compromised, root-filled teeth: a case report. Quintessence Int 1999; 30(9):601-6.

23. Pontius O, Hutter JW. Survival rate and fracture strength of incisors restored with different post and core systems and endodontically treated incisors without coronoradicular reinforcement. J Endod 2002; 28:710-5.

24. Lawley GR, Schindler WG, Walker WA, Kolodrubetz D. Evaluation of ultrasonically placed MTA and fracture resistance with intracanal composite resin in a model of apexification. J Endod 2004; 30:167-72.

25. Chittem J, Sajjan GS, Varma KM. Comparative evaluation of microshear bond strength of the caries-affected dentinal surface treated with conventional method and chemome chanical method (papain). J Conserv Dent 2015; 18:369373.

26. Condon J. Assessing the Effects of Composite Formulation on Polymerization stress, J Am Dent Assoc 2000; 131(4): 497-503. 
27. Ferracane JL. Glass ionomer liner reduces contraction stress. Oper Dent 2008; 33(3):247-57.

28. Yamazaki PC. Microleakage evaluation of a new lowshrinkage composite restorative material. Oper Dent 2006; 31(6): 670-6.

29. Truffier-Boutry D. A physic-chemical explanation of the post- polymerization shrinkage in dental resins. Dent Mater 2006; 22(5): 405-12.

30. Hambire UV, Tripathi VK. Influence of zirconia nanoclusters on the compressive strength of BIS-GMA and TEGDMA based dental composites. J Eng App Sci 2012; 7:1196-1201.

31. Alkhudhairy F, Vohra F. Adhesive bond strength and compressive strength of a novel bulk fill composite with zirconia nano-hybrid filler. J Adhes Sci Technol 2016; 1-10.

32. Helvatjoglu-Antoniades M, Koliniotou-Kubia E, Dionyssopoulos P. The effect of thermal cycling on the bovine dentine shear bond strength of current adhesive systems. J Oral Rehabil 2004; 31:911-7.

33. Yoldas O, Alaçam T. Microhardness of composites in simulated root canals cured with light transmitting posts and glass-fiber reinforced composite posts. J Endod 2005; 31(2):104-6.

34. Ilie N, Bucuta S, Draenert M. Bulk-fill resin-based composites: an in vitro assessment of their mechanical performance. Oper Dent 2013; 38(6):618-25.

35. Moszner N, Fischer UK, Ganster B, Liska R, Rheinberger V. Benzoyl germanium derivatives as novel visible light photoinitiators for dental materials. Dent Mater 2008; 24(7):901-7.

36. Hayashi M, Takahashi Y, Hirai M, Iwami Y, Imazato S, Ebisu S. Effects of endodontic irrigation on bonding of resin cement to radicular dentin. Eur J Oral Sci 2005; 113:70-6.

37. Hashimoto M, Ohno H, Kaga M, Endo K, Sano H, Oguchi $\mathrm{H}$. Resin tooth adhesive interfaces after long term function. Am J Dent 2001; 14:211-5.

38. Major IA, Smith MR, Mannocci F. The structure of denting in the apical region of human teeth. Int Endod J 2001; 34:346-53.

39. Ferrari M, Vichi A, Grandini S, Goracci C. Efficacy of a self-curing adhesive/resin cement system on luting glassfiber posts into root canals: an SEM investigation. Int $\mathrm{J}$ Prosthodont 2001; 14:543-9.

40. Segreto D, Brandt WC, Correr-Sobrinho L, Sinhoreti MAC, Consani S. Influence of irradiance on the push-out bond strength of composite restorations photoactivated by LED. J Contemp Dent Pract 2008; 9(2): 89-96.

41. Mosharrafian Sh, Sharifi Z. Comparison of push-out bond strength of two bulk-fill and one conventional composite to intracanal dentin in severely damaged primary anterior teeth. Tehran Univ Med Sci 2016; 13(3):207-14.

42. Garoushi S, Säilynoja E, Vallittu PK, Lassila L. Physical properties and depth of cure of a new short fiber reinforced composite. Dent Mater 2013; 29: 835-41. 